\title{
Establishment of a Pathogenicity Index for One-day- old Broilers to Pasteurella multocida Strains Isolated from Clinical Cases in Poultry and Swine
}

\section{-Author(s)}

\section{Pilatti RM ${ }^{\prime}$ \\ Furian TQ' \\ Lima DA' \\ Finkler F" \\ Brito BG" \\ Salle CTP \\ Moraes HLS'}

Departamento de Medicina Animal, Centro de Diagnóstico e Pesquisa em Patologia Aviária (CDPA), Faculdade de Veterinária (FAVET), Universidade Federal do Rio Grande do Sul (UFRGS), Porto Alegre, RS, Brazil.

" Instituto de Pesquisas Veterinárias Desidério Finamor (IVDF), Eldorado do Sul, RS, Brazil.

\section{Mail Address}

Corresponding author e-mail address Roberta Pilatti

Av. Bento Gonçalves, 8824

91540-000. Porto Alegre,RS,Brazil

Phone: (5554) 3308-6130/6138

Email: pilatti.roberta@gmail.com

\section{-Keywords}

Fowl cholera, inoculation, Pasteurella multocida, pathogenicity index.

\section{ABSTRACT}

Although Pasteurella multocida is a member of the respiratory microbiota, under some circumstances, it is a primary agent of diseases , such as fowl cholera ( $F C$ ), that cause significant economic losses. Experimental inoculations can be employed to evaluate the pathogenicity of strains, but the results are usually subjective and knowledge on the pathogenesis of this agent is still limited. The objective of this study was to establish a new methodology for classifying the pathogenicity of $P$. multocida by formulating a standard index. Strains isolated from FC cases and from swine with respiratory problems were selected. One hundred $\mu \mathrm{L}$ of a bacterial culture of each strain, containing $10^{6} \mathrm{CFU}$, was inoculated in 10 one-day-old broilers. Mortality after inoculation, time of death (TD), and the presence of six macroscopic lesions were evaluated over a period of seven days post-inoculation (dpi). A Pathogenicity Index Per Bird (IPI), ranging 0 to 10, was calculated. Liver and heart fragments were collected to reisolate the bacteria. Blood was collected from the surviving birds, and an ELISA test was carried out to detect specific antibodies. The median of the pathogenicity indices, the number of lesions and the rate of bacteria reisolation were significantly different $(p<0.05)$ among the origins of the isolates $(p<0.05)$. The pathogenicity index developed in this study allows the classification of Pasteurella multocida pathogenicity and may be an alternative to the pathogenicity models currently used for screening.

\section{INTRODUCTION}

Pasteurella multocida is a member of the commensal flora of the upper respiratory tract in animals. Under stress conditions, it may be involved in various respiratory syndromes as a secondary agent (Nascimento et al., 2009). This microorganism also causes other diseases in livestock, such as hemorrhagic septicemia in ruminants, atrophic rhinitis in swine, and fowl cholera (FC) in poultry (Boyce et al., 2004).

Despite the wide spectrum of diseases that it causes and the economic losses associated with pasteurellosis, the knowledge of the pathogenesis of this agent remains limited (Wilkie et al., 2012). Studies on Pasteurella virulence genes (Ewers et al.,2006; Furian et al., 2013; Tang et al., 2009) and in in-vitro transcription analyses determined that the pathogenic strain is critical because $P$. multocida is an opportunistic microorganism in vertebrates (Christensen \& Bisgaard, 2006). Thus, the inoculation of animals such as rodents, chicks, and embryonated eggs is used in some studies to determine the pathogenicity of isolates (Ibrahim et al., 1998; Mohamed et al., 2012; Schivachandra et al., 2006). In addition, the inoculation of materials suspected to cause disease in mice with subsequent isolation of pure cultures of bacteria is a diagnostic tool for FC (Dziva et al., 2008), but this method is not considered adequate to evaluate pathogenicity (Mohamed et al., 2012; Schivachandra et al., 2006). 
However, studies aiming at determining the pathogenicity and classifying P. multocida avian and swine isolates are rare, and often subjective, regarding the presence of macroscopic lesions. The objective of this study was to establish a classification model for the pathogenicity of $P$. multocida strains isolated from poultry and pigs by inoculating one-day-old broilers.

\section{MATERIALS AND METHODS}

\section{Experimental animals}

A total of 960 one-day-old broilers derived from 58-week-old broiler breeder not vaccinated against FC were acquired for the study. Birds were randomly assigned to groups of 10 individuals and housed in pens $(30 \mathrm{~cm}$ of length $\times 55 \mathrm{~cm}$ of height $\times 35 \mathrm{~cm}$ of width) located in an isolation room with controlled temperature $\left(32^{\circ} \mathrm{C}\right)$. Drinking water and commercial feed were provided ad libitum.

The research project complied with professional and institutional animal welfare policies and was approved by the Ethics Committee on Animal Use (CEUA) of the Veterinary Research Institute Desiderio Finamor (IPVDF), protocol number 25/2012.

\section{Strains of Pasteurella multocida}

Ninety-six strains of $P$. multocida were selected for the study: 54 strains previously isolated from clinical cases of FC, 40 strains isolated from pigs with respiratory signs, and two reference strains from the American Type Culture Collection (ATCC - American Type Culture, Manassas, VA, United States of America), numbers 15742 and 12945, isolated from turkeys and chickens, respectively. The strains were stored in sheep blood at $-80{ }^{\circ} \mathrm{C}$ and reactivated according to Glisson et al. (2008). An aliquot of each sample was inoculated into brain heart infusion broth (BHI - Oxoid; Cambridge, United Kingdom) and incubated at 37 ${ }^{\circ} \mathrm{C}$ for 24 hours. After this period, the samples were plated on blood agar (BA - Oxoid; Cambridge, United Kingdom) supplemented with $5 \%$ defibrinated sheep blood and on MacConkey agar (Oxoid; Cambridge, United Kingdom). The colonies in BA were evaluated according to their morphology. Catalase and oxidase tests were performed in addition to methylene blue staining to visualize the bipolar bacterial cells. Finally, the strains were subjected to a species-specific PCR protocol to detect the gene $k m t 1$, according to the protocol developed by Townsend et al. (1998).

\section{Lethal Dose $\mathbf{5 0 \%}\left(\mathrm{LD}_{\mathbf{5 0}}\right)$}

Five strains of $P$. multocida were selected, including the reference strains ATCC 15742 and ATCC 12945.
Bacterial cultures grown in $\mathrm{BHI}$ overnight at $37^{\circ} \mathrm{C}$ containing $10^{8} \mathrm{CFU} / / \mathrm{mL}$ were serially diluted to a final dilution of $10^{-9}$ by transferring $1 \mathrm{~mL}$ of the initial suspension to a tube containing $9 \mathrm{~mL}$ of $0.85 \%$ sterile saline. Each dilution was inoculated $(0.1 \mathrm{~mL})$ in 10 one-day-old broilers intraperitoneally. After a pilot project, in which $100 \%$ of birds mortality with $10^{9} \mathrm{CFU}$ inoculation dose (Souza, 2010) in less than 24 hours was observed, the $\mathrm{LD}_{50}$ was determined according the methodology described by Reed \& Muench (1938). The $L_{50}$ presented a value of approximately $10^{5} \mathrm{CFU}$.

\section{Inoculum preparation}

The inoculum preparation was standardized for all strains, according to the technique described by Borsoi et al. (2009) with modifications. After cultivation of each sample in BA overnight at $37^{\circ} \mathrm{C}$, a colony was selected and transferred to a tube containing $5 \mathrm{~mL}$ of $\mathrm{BHI}$. After the cells were suspended, the solutions were homogenized and serially diluted to a final dilution of $10^{-9}$ by transferring $1 \mathrm{~mL}$ of the initial suspension to a tube containing $9 \mathrm{~mL}$ of $0.85 \%$ sterile saline. A bacterial count was performed in BA for each dilution by the drop technique (Tortora \& Case, 2012; Trabulsi \& Alterthum, 2008). The standard inoculum solution containing $10^{6}$ $\mathrm{CFU} / \mathrm{mL}$ was utilized to inoculate the chicks.

\section{Inoculation}

The groups of 10 one-day old broilers were intraperitoneally inoculated with $0.1 \mathrm{~mL}$ of the standard inoculum solutions containing each of the 96 P. multocida strains. A control group of 10 broilers of the same age was also inoculated with $0.1 \mathrm{~mL}$ of $0.85 \%$ sterile saline by the same route. Four experimental series were performed for the inoculation of all strains. Birds were observed for a period of seven days postinoculation (dpi).

Mortality, evaluation of the presence of macroscopic lesions and bacterial reisolation

The birds were observed every $12 \mathrm{~h}$ for seven consecutive days and mortality was recorded. At each visit, the dead birds were collected for necropsy and for macroscopic evaluation of the presence of the following lesions: pericarditis $(\mathrm{PC})$, perihepatitis $(\mathrm{PH})$, peritonitis (PT), airsacculitis (A), cellulitis $(C L)$, and omphalitis (ONF).

Simultaneously, fragments of the liver and heart were collected from the birds and inoculated with $5 \mathrm{~mL}$ of $\mathrm{BHI}$ for bacterial reisolation, as described by Christensen \& Bisgaard (2006). Blood was collected from the surviving birds by cardiac puncture $7 \mathrm{dpi}$. An indirect ELISA (IDEXX 
Laboratories, Westbrook, ME, United States of America) test using a commercial kit was carried out to detect antibodies specific to P. multocida. The birds were euthanized and then necropsied to assess the presence of macroscopic lesions and for bacterial reisolation, as previously mentioned.

\section{Calculation of Pathogenicity Index Per Bird (IPI)}

The IPI corresponds to the pathogenicity index for each bird in each group inoculated with a strain of $P$. multocida. The calculation of the IPI was based on a study by Souza et al., (2016) with modifications. A value of 10 was established as the maximum pathogenicity rate for an inoculated bird. In this index, 5 points corresponded to the time of death (TD) and its survival bonus factor (FBS). To obtain the TD value, an index of 1 (which corresponded to the maximum value assigned to a death on the first day) was divided by the number of days the birds were evaluated (7 days), resulting in a value of 0.1428 , which corresponded to the FBS. Thus, every day that the birds survived discounted 0.1428 of the TD value. The remaining 5 points corresponded to scores for gross lesions (GL) present at necropsy (Souza, 2010). The GL value was determined by dividing the maximum score assigned to this indicator ( 5 points) by the number of lesions (6), obtaining a value of 0.833 , indicating the presence of each lesion. The remaining birds did not receive were not scored for TD at the end of the seven days of observation; only the respective $G L$ values were counted for the IPI. Therefore, the IPI was calculated according to the following equation:

${ }^{*} \mathrm{IPI}=(\mathrm{TD} \times 5)+\mathrm{PC}+\mathrm{PH}+\mathrm{PT}+\mathrm{ASS}+\mathrm{CL}+\mathrm{ONF}$

IPI: Pathogenicity Index Per Bird; TD: time of death; PC: pericarditis; PH: perihepatitis; PT: peritonitis; ASS: airsacculitis; CL: cellulitis; ONF: omphalitis.

The Pathogenicity Index (IP) for each inoculated strain was calculated according to the given equation:

$$
* \mid \mathrm{P}=\sum(\mid \mathrm{PI})
$$

$\mathrm{N}$

* IP: Pathogenicity Index; IPI $\Sigma$ : sum of Pathogenicity Indices Per Bird; N: number of inoculated birds.

\section{Statistical Analysis}

Mann Whitney, Kruskal-Wallis and Dunn's nonparametric statistical tests were selected for the analysis of the results, using the statistical program GraphPad PRISM $^{\circledR} 6$ at significance level of $5 \%$ and confidence level of $95 \%$.

\section{RESULTS}

At the end of the observation period, $75.7 \%$ of the birds inoculated with avian strains and $36.7 \%$ of those inoculated with pig isolates died. Mortality significantly higher $(p<0.05)$ in the birds inoculated with avian strains than in those challenged with pig strains isolated on 1, 2, and 4 dpi, as shown in Table 1. Similarly, the highest mortality occurred during the first 72 hours post-inoculation, regardless of the host origin.

Table 1 - Relative frequency (\%) of mortality observed during seven days after inoculation of one-day-old broilers according to $P$. multocida strain origin.

\begin{tabular}{ccccccccc}
\hline \multirow{2}{*}{ Origin } & 1 & 2 & 3 & 4 & 5 & 6 & 7 & $7^{\star}$ \\
\cline { 2 - 8 } Avian & $56.1^{\mathrm{a}}$ & $13.6^{\mathrm{a}}$ & $3.0^{\mathrm{a}}$ & $1.6^{\mathrm{a}}$ & $0.5^{\mathrm{a}}$ & $0.2^{\mathrm{a}}$ & $0.7^{\mathrm{a}}$ & $24.3^{\mathrm{a}}$ \\
Swine & $19.3^{\mathrm{b}}$ & $8.3^{\mathrm{b}}$ & $6.3^{\mathrm{a}}$ & $0.7^{\mathrm{b}}$ & $0.7^{\mathrm{a}}$ & $1.2^{\mathrm{a}}$ & $0.2^{\mathrm{a}}$ & $63.3^{\mathrm{b}}$ \\
\hline
\end{tabular}

*birds euthanized at the end of the study. Different letters in the same column indicate significant differences between groups $(p<0.05)$, Dunn's test.

All lesions were identified in at least one animal in each group inoculated with the P. multocida strains. Peritonitis and omphalitis were more common. Although the difference was not significant ( $p>0.05)$, macroscopic lesions assessed during the post-mortem examination of the 10 animals inoculated with each strain were observed in fewer animals inoculated with swine strains than with avian strains (Table 2).

In the study, all strains inoculated were re-isolated from at least one of the challenged animals in each group, but the frequency of reisolation was low, particularly from 3 dpi. However, it was also observed that the avian strains were re-isolated at a higher frequency $(p<0.05)$ than the swine strains (Table

Table 2 - Median of macroscopic lesions present in groups of 10 birds inoculated with each strain according to the origin of the strains.

\begin{tabular}{|c|c|c|c|c|c|c|c|}
\hline \multirow[b]{2}{*}{ Origin } & \multirow[b]{2}{*}{$N^{\circ}$} & \multicolumn{6}{|c|}{ Median of macroscopic lesions \pm standard deviation } \\
\hline & & $C L^{*}$ & $P C^{*}$ & $\mathrm{PH}^{*}$ & $\mathrm{PT}^{*}$ & ASS* & ONF* \\
\hline Avian & 56 & $6,5 \pm 2,54^{a}$ & $3.0 \pm 2.62^{a}$ & $4.5 \pm 2.33^{a}$ & $9.0 \pm 2.87^{a}$ & $7.0 \pm 2.30^{a}$ & $9.0 \pm 2.18^{a}$ \\
\hline Swine & 40 & $6,0 \pm 3,14^{a}$ & $1.0 \pm 1.53^{a}$ & $2.0 \pm 2.14^{\mathrm{a}}$ & $8.0 \pm 2.32^{a}$ & $6.0 \pm 2.35^{a}$ & $7.0 \pm 2.61^{a}$ \\
\hline
\end{tabular}

${ }^{*} \mathrm{CL}$ : cellulitis; PC: pericarditis; PH: perihepatitis; PT: peritonitis; ASS: airsacculitis; ONF: omphalitis. Different letters in the same column represent significant differences between groups $(p<0.05)-$ Dunn's test. 
3). None of the serum samples collected on $7 \mathrm{dpi}$ presented antibody titers in the ELISA test.

Table 3 - Relative frequency (\%) of the reisolation of inoculated Pasteurella multocida strains and the median pathogenicity index (PI) according to the strain origin.

\begin{tabular}{llll}
\hline Origin & $\mathrm{N}^{\circ}$ of strains & \% reisolation & $\mathrm{IP}$ \\
\hline Avian & 56 & $54.64^{\mathrm{a}}$ & $7.19 \pm 2.67^{\mathrm{a}}$ \\
Swine & 40 & $31.95^{\mathrm{b}}$ & $4.13 \pm 2.57^{\mathrm{b}}$ \\
\hline
\end{tabular}

Different letters in the same column represent significant difference between the groups $(p<0.05)$ - Kruskal-Wallis test.

Based on mortality frequency and the presence of macroscopic lesions, an IP was calculated for the avian and swine strains. According to significant differences in mortality and frequency of the lesions, the median of pathogenicity indices indicated differences between the origins $(p<0.05)$, as shown in Table 3.

The 96 strains of $P$. multocida were classified into three pathogenicity groups according to the $I P$, as shown in Table 4 . The results show a significant difference $(p<0.05)$ in the median IP values among the groups.

Table 4 - Median values of Pathogenicity Index (IP) obtained according to the distribution of avian and swine strains of Pasteurella multocida inoculated in the pathogenicity groups.

\begin{tabular}{lcc}
\hline Pathogenicity Group & N. of strains & Median \pm standard deviation \\
\hline High (IP from 8 to 10) & 37 & $9,13 \pm 0,953^{\mathrm{a}}$ \\
Intermediate (IP from 4 to 7) & 35 & $5,24 \pm 1,159^{\mathrm{b}}$ \\
Low (IP from 0 to 3) & 24 & $1,75 \pm 0,837^{\mathrm{c}}$ \\
\hline
\end{tabular}

Different letters in the same column represent a significant difference between the groups $(p<0.05)$, Kruskal-Wallis test.

\section{DISCUSSION}

A higher mortality in birds inoculated with avian strains was observed in this study. A similar result was found in the study of Wilkie et al. (2000), in which chickens experimentally inoculated with a highly-pathogenic strain died within 22 to 23 hours after challenge and animals that were inoculated with a low pathogenicity strain died within 72 hours after challenge. Furthermore, the acute form of FC usually causes the rapid death of the host due tothe characteristic septicemia caused by the microorganism (Boyce et al., 2006).

A lower numerical frequency of macroscopic lesions was detected in the chicks inoculated with swine strains than with avian strains, but no statistical difference between strain origins was observed. The specificity of the strains related to the species of the challenged animals may explain this variation. The lesions evaluated in the study have also been described in several papers, in which diagnostic tests were performed to confirm clinical cases of pasteurellosis (Nunes et al., 2008; Rahman et al., 2004; Zhang et al., 2004). However, it is only possible to correlated macroscopic findings with the etiological agent via bacteriological diagnosis because the macroscopic lesions caused by Escherichia coli and other bacteria are very similar to those caused by P. multocida (Bisgaard \& Dam, 1980; Fisher et al., 1998).

Differences in the daily mortality rates and the relative frequency of lesions associated with the strain origin may explain the low percentage of bacterial reisolation. The persistence of the bacteria at the site of infection, as well as their migration to other tissues and the time of death depend on the characteristics of the strain or on the host immune response (Boyce et al., 2010; Wilkie et al., 2012) and may influence microorganism isolation. The death caused by avian strains occurred primarily within the first $2 \mathrm{dpi}$. Although the isolation of the agent in non-selective media with a lower risk of growth of other bacteria is more likely until 2 dpi (Dziva et al., 2008), P. multocida was isolated on all days of observation, but in decreasing numbers as the number of days after inoculation increased.

No antibody titers were detected in none of the serum samples by ELISA, possibly because the observation period was insufficient for the development of a detectable lgG immune response. Chaudhuri et al. (2012) evaluated the humoral immune response of mice and rabbits inoculated with $P$. multocida. Both species presented antibody titers, but the test was performed 10 days after the first inoculation. Additionally, Wilkie et al. (2000) inoculated chickens twice in an interval of 28 days, and observed that the serum samples collected after the first inoculation on 7 dpi presented lower titers, whereas those collected on 30 dpi had higher titers.

The median of the pathogenicity index was different between the strain origin, although literature reports that strains isolated from pigs tend to be highly virulent in birds (Glisson, 2008). However, Hazarika et al. (2011) noted that isolates from swine were not equally virulent when inoculated in mice. The lack of available studies on the pathogenicity of $P$. multocida in vivo, except for studies of inoculation in mice to determine the $\mathrm{LD}_{50}$, makes it difficult to compare these data.

\section{CONCLUSIONS}

The time of death and the presence of macroscopic lesions allowed for the classification of strains for 
different levels of pathogenicity. This methodology can be used in the future to assess the pathogenicity of $P$. multocida in diseases in which it is the primary agent, particularly in cases of respiratory syndromes from which the bacterium is commonly isolated.

\section{ACKNOWLEDGEMENTS}

The authors thank the National Council for Scientific and Technological Development (CNPq) for funding this project (project number 578046/2008-3).

\section{ETHICAL APPROVAL}

The research project complied with professional and institutional animal welfare policies and was approved by the Ethics Committee on Animal Use (CEUA) of the Veterinary Research Institute Desiderio Finamor (IPVDF), located in Eldorado do Sul, State of Rio Grande do Sul, protocol number 25/2012.

\section{REFERENCES}

Bisgaard M, Dam A. Salpingitis in poultry. I. Prevalence, bacteriology, and possible pathogenesis in broilers. Nordordisk Veterinaer Medicin 1980;32(9):361-368.

Borsoi A, Santin E, Santos LR, Salle CT, Moraes HL, Nascimento VP. Inoculation of newly hatched broiler chicks with two Brazilian isolates of Salmonella Heidelberg strains with different virulence gene profiles, antimicrobial resistance, and pulsed field gel electrophoresis patterns to intestinal changes evaluation. Poultry Science 2009;88(4):750-758.

Boyce JD, Harper M, Wilkie IW, Adler B. Pasteurella. In: Gyles CL, Prescott $\mathrm{JF}$, Songer $\mathrm{G}$, Thoen $\mathrm{CO}$, editors. Pathogenesis of bacterial infections in animals. 4th ed. Ames: Blackwell Publishing; 2010. p.325-346.

Boyce JD, Adler B. How does Pasteurella multocida respond to the host environment? Current Opinion in Microbiology 2006;9(1):117-122.

Boyce JD, Wilkie I, Harper M, Paustian ML, Kapur V, Adler B. Genomicscale analysis of Pasteurella multocida gene expression during growth within liver tissue of chickens with fowl cholera. Microbes and Infection 2004;6(3):290-298.

Chaudhuri P, Singh VP, Thamizharasan A, Lalsiamthara J. Pasteurella multocida P52 aroA mutant conferred protection to rabbits and mice against haemorrhagic septicaemia. DHR International Journal of Biomedical and Life Sciences 2012; 3(1): 2278-8301.

Christensen H, Bisgaard M. The genus Pasteurella. In: Dworkin M, Falkow S, Rosenberg E, Schleifer KH, Stackebrandt E, editors. The Prokaryotes. 3rd ed. Berlin: Springer-Verlag; 2006. p.1062-1090.

Dziva F, Muhairwa AP, Bisgaard M, Christensen H. Diagnostic and typing options for investigating diseases associated with Pasteurella multocida. Veterinary Microbiology 2008;128(1-2):1-22.

Ewers C, Lübke-Becker A, Bethe A, Kiebling S, Filter M, Wieler LH. Virulence genotype of Pasteurella multocida strains isolated from different hosts with various disease status. Veterinary Microbiology 2006;114(34):304-317

Fisher ME, Trampel DW, Griffith RW. PosTDortem detection of acute septicemia in broilers. Avian Diseases 1998;42(3):452-461.
Furian TQ, Borges KA, Rocha SLS, Rodrigues EE, Nascimento VPD, Salle CTP Moraes HLS. Detection of virulence-associated genes of Pasteurella multocida isolated from cases of fowl cholera by multiplex-PCR. Pesquisa Veterinária Brasileira 2013;33(2):177-182.

Glisson JR. Pasteurellosis and other respiratory bacterial infections. In: Saif YM, Fadly AM, Glisson JR, McDougald LR, Nolan LK, Swayne DE, editors. Diseases of poultry. 12th ed. Hoboken: Blackwell Publishing; 2008. p.739-758

Glisson JR, Sandhu TS, Hofacre CL. Pasteurellosis, avibacteriosis, gallibacteriosis, riemerellosis and pseudotuberculosis. In: DufourZavala L, editor. A laboratory manual for the isolation, identification and characterization of avian pathogens. 5th ed. Athens: American Association of Avian Pathologists; 2008. p.12-18.

Hazarika MP, Barman NN, Gerorge S, Sharma RK. Characterization of Pasteurella multocida isolated from pneumonic pigs of Assam. Indian Journal of Animal Research 2011;44(4):265-269.

Ibrahim RS, Sawada T, El-Ballal S, Shahata M, Yoshida T, Kataoka Y. Pasteurella multocida infection in the chicken embryo. Journal of Comparative Pathology 1998;118(4):291-300.

Mohamed MA, Mohamed MW, Ahmed Al, Ibrahim AA, Ahmed MS. Pasteurella multocida in backyard chickens in Upper Egypt: incidence with polymerase chain reaction analysis for capsule type, virulence in chicken embryos and antimicrobial resistence. Veterinaria Italiana 2012;48(1): 77-86

Nascimento VP, Gama NMSQ, Canal CW. Coriza Infecciosa das galinhas, pasteurelose e outras infecções bacterianas. In: Berchieri JA, Silva EN, Fábio JD, Sesti L, Zuanaze MAF, editors. Doenças das aves. $2^{\text {a }}$ ed. Campinas: FACTA: 2009. p.512-521.

Nunes CF, Vilela C de O, Caetano CF, Munhoz L, Raffi MB, Finger PF, Siedler $B$, Fisher G, Ferreira LN, Vargas GD. Ascaridíase e pasteurelose em aves de criação colonial. Anais do $35^{\circ}$ Congresso Brasileiro de Medicina Veterinária; 2008; Gramado, Rio Grande do Sul. Brasil. p.450.

Rahman MA, Samad MA, Rahman MB, Kabir ML. Bacterio-pathological studies on Salmonellosis, Colibacillosis and Pasteurellosis in natural and experimental infections in chickens. Bangladesh Journal of Veterinary Medicine 2004;2(1):1-8

Reed $\mathrm{L}$, Muench $\mathrm{H}$. A simple method of estimating 50 per cent endpoint. American Journal of Hygiene 1938;27(3):493-497

Shivachandra SB, Kumar AA, Gautam R, Joseph S, Chaudhuri P, Saxena MK, Srivastava SK, Singh N. Detection of Pasteurella multocida in experimentally infected embryonated chicken eggs by PCR assay. Indian Journal of Experimental Biology 2006;44(4):321-324.

SOUZA, G. F.; ROCHA, S. L. S.; FURIAN, T. Q.; BORGES, K. A.; SALLE, F. O.; MORAES, L. B.; MORAES, H. L. S. e SALLE, C. T. P. Classification of Avian Pathogenic Escherichia coli by a Novel Pathogenicity Index Based on a Animal Model. Acta Scientiae Veterinareae. 2016. v. 44. n. 1347.

Tang X, Zhao Z, Hu J, Wu B, Cai X, He Q, Chen H. Isolation, antimicrobial resistance, and virulence genes of Pasteurella multocida strains from swine in China. Journal of Clinical Microbiology 2009; 47(4):951-958.

Tortora GJ, Funke BR, Case CL. Crescimento bacteriano. In: Tortora GJ, funke BR, Case CL. Microbiologia. 10ª ed. Porto Alegre: ArTDed; 2012. p.156-183.

Townsend KM, Frost AJ, Lee CW, Papadimitriou JM, Dawkins HJ. Development of PCR assays for species- and type-specific identification of Pasteurella multocida isolates. Journal of Clinical Microbiology 1998;6(4):1096-1100

Trabulsi LR, Alterthum F. Crescimento bacteriano. In: Trabulsi LR, Alterthum F. Microbiologia. $5^{a}$ ed. São Paulo: Atheneu; 2008. p.31-36. 
Wilkie IW, Grimes SE, O'Boyle D, Frost AJ. The virulence and protective efficacy for chickens of Pasteurella multocida administered by different routes. Veterinary Microbiology 2000;72(1-2):57-68.

Wilkie IW, Harper M, Boyce JD, Adler B. Pasteurella multocida: diseases and pathogenesis. Current Topics in Microbiology and Immunology 2012;361: 1-22
Zhang P, Fegan N, Fraser I, Duffy P, Bowles R, Gordon A, Ketterer PJ, Shinwari W, Blackall PJ. Molecular epidemiology of two fowl cholera outbreaks on a free-range layer farm. Journal of Veterinary Diagnostic Investigation 2004;16(5):458-460. 